\title{
Load Compensation Performance of DSTATCOM with Hysteresis and Adaptive Hysteresis Current Controllers in Distribution Systems
}

\author{
Sura srinivasa rao ${ }^{\# 1}$, Dr. Sai Babu choppavarapu ${ }^{* 2}$ \\ \# Asst.professor, EEE Department, GITAM University, Visakhapatnam, India ${ }^{1}$ \\ srinu722@gmail.com \\ *Professor, JNTU University, JNTU Kakinada, India \\ 2 chs_eee@yahoo.co.in
}

\begin{abstract}
D-STATCOM) are used to alleviate current related power quality problems in distribution systems. The main purpose of D-STATCOM is to reduce harmonics in source side of system. In D-STATCOM, reference filter currents are generated by instantaneous symmetrical component theory. Switching pulses for Voltage source inverter(VSI) are given by comparing filter currents with actual source currents. In this paper, performance of D-STATCOM in terms of harmonic reduction, for fixed hysteresis current control scheme(HCC) and variable band hysteresis current controller(AHCC) is proposed. The load side and source side harmonics of the system for both switching controllers are compared by using MATLAB/SIMULINK and \%Total Harmonic distortion(THD) is less in case of AHCC.
\end{abstract}

Keyword- Distribution static compensator, harmonics, hysteresis and Adoptive current control, custom power devices.

\section{Introduction}

Increased application of power electronics devices leads to higher harmonic currents thereby degrading the power quality of the distribution system. Harmonic currents in power system result in transformer overheating, rotary machine vibration, and voltage quality degradation. To overcome the above mentioned problems, active power filters have been proposed by researchers. In 1970's, their basic principles were discussed by Sasaki and Machinda (1971), Peterson et al (1975), Gyugyi and Srycula (1976), Mohan et al (1977). High power modern semiconductor switches such as IGBTs GTOs and thyristors have enabled the practical incorporation of active power filters. These active devices used in distribution system are given a generic name as Custom Power devices and are discussed by Salmeron and Litran (2010), Brenna et al (2009). Distribution static compensator (D-STATCOM) type custom power devices which is connected in shunt to the load at the load center. When the load is unbalanced and nonlinear due to distorted load currents harmonics are injected into the system. By the implementation of D-STATCOM we can make the harmonic free sinusoidal source current with unity power factor operation and reactive power flow control. Different types of Voltage Source Inverter (VSI) based DSTATCOM are discussed by Iyer et al (2005), George and Mahesh Mishra (2010), vodyakho and Kim(2009), three leg DSTATCOM is used because it has a it has a single input DC capacitor and it does not have a problem of capacitor voltage balancing. Hence, in the present work a three leg D-STATCOM concept is proposed which requires a lower dc input voltage and has a passive capacitor and inductor as interface elements. THDs (\%) of compensated source currents, PCC voltages are also presented and the results are shown in the simulation studies.

\section{NEUTRAL CLAMPED VSI TOPOLOGY}

The conventional three phase voltage source inverter (VSI) topology (S. Iyer et al,2005) consists of six switches each device with an anti-parallel diode and a single input capacitor. In this topology, the zero sequence currents in the load cannot be compensated and hence the zero sequence currents flow in the neutral wire (N-n) between the system and the load, thus degrading the power quality. The D-STATCOM injected filter currents are not independent because their algebraic sum is zero.

In this paper, Neutral clamped VSI topology, Fig. 1, to compensate zero sequence currents in the load is proposed. The topology has six power semiconductor switches with an anti-parallel diode and two identical dc storage capacitors. The currents if $a$, if $b$, if $c$ represents the actual filter currents obtained using hysteresis and adaptive hysteresis current control technique (S. Srikanthan et al, 2008), and the isa, isb, isc represents the source currents. Input voltage of VSI is maintained at reference value (Vdcref) with a storage dc capacitor with capacitance $\mathrm{Cdc}$. The two dc capacitors are charged to different voltages, to compensate dc components in VSI. 
However, voltage across dc capacitors is maintained constant by using a PI voltage control loop. Drift in the dc capacitor voltage from the reference value occurs due to several factors such as dc current in load, unequal capacitance leakage currents, and unequal delays in the semiconductor devices (Nabae et al, 1981; Aredes et al, 1997; Srinivasan and Oruganti, 1998; singh et al, 2004).

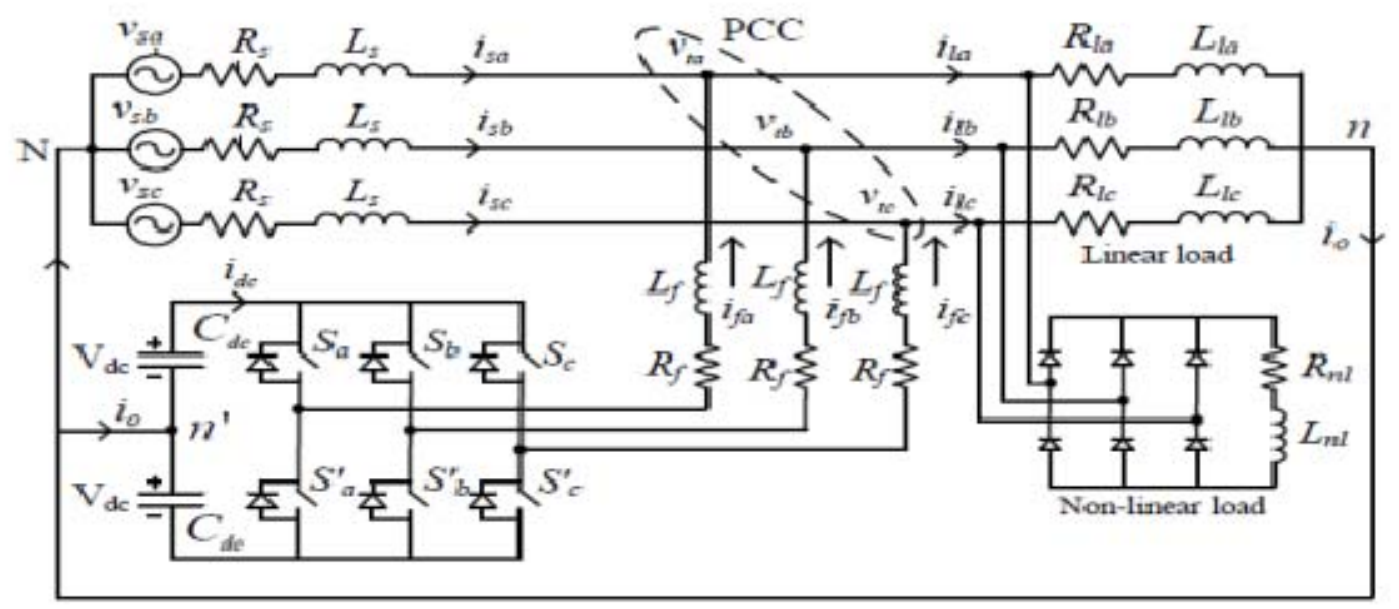

Fig.1. Diagram of three-phase, four wire neutral clamped VSI topology

\section{GENERATION OF INJECTED FILTER CURRENTS AND SWITCHING CONTROL STRATEGY}

The injected filter currents are obtained from the theory of instantaneous symmetrical component and the detail explanation can be shown below.

\section{A. Instantaneous Symmetrical Component Theory}

The theory of instantaneous symmetrical component (Ghosh and Joshi, 1998; Ghosh and Joshi, 2000a; Ghosh and Joshi, 2000b) is used in this study. The control algorithm based on the instantaneous symmetrical component theory can practically compensate for any kind of unbalance and harmonics in the load using high bandwidth current sources to track the filter reference currents as discussed by Karthikeyan and Kumar Mishra (2007), and they have given the filter current expressions as:

$$
\begin{aligned}
& i_{f a}^{*}=i_{l a}-i_{s a}^{*}=i_{l a}-\frac{v_{s a}+\gamma\left(v_{s b}-v_{s c}\right)}{\Delta}\left(p_{\text {lavg }}+p_{\text {loss }}\right)--(1) \\
& i_{f b}^{*}=i_{l b}-i_{s b}^{*}=i_{l b}-\frac{v_{s b 1}+\gamma\left(v_{s c}-v_{s a}\right)}{\Delta}\left(p_{\text {lavg }}+p_{\text {loss }}\right)--(2) \\
& i_{f c}^{*}=i_{l c}-i_{s c}^{*}=i_{l c}-\frac{v_{s c 1}+\gamma\left(v_{s a}-v_{s b}\right)}{\Delta}\left(p_{\text {lavg }}+p_{\text {loss }}\right)--(3)
\end{aligned}
$$

From the above reference current expressions it is observed that this scheme based on instantaneous symmetrical components is computationally much simpler than p-q theory ( Lyon, 1954; Akagi et al, 1993; Furuhashi et al, 1990; Ferrero and Furga, 1991; Williems, 1992; peng and Lai, 1996; peng et al, 1998). Balanced sinusoids and unity power factor source currents for all kinds of loads can be obtained from the scheme proposed. Further, source currents at an arbitrary power factor angle can also be generated.

\section{B. Switching Control Strategy}

The switching control strategy of hysteresis current controller (HCC) and Adaptive hysteresis current controller (AHCC) can be explained as

\section{a. Hysteresis Current Controller}

Hysteresis current controller consists of bands which are above and below the reference quantities and there are represented as $+\mathrm{h}$ and $-\mathrm{h}$. The switching commands are directly given to the top switches in legs and their complementary signals to the bottom switches. Switching commands are generated from the switching logic given below:

For Iinv< $\left(\mathrm{I}^{*}\right.$ inv- $\left.\mathrm{h} b\right)$, lower switch S4 will be ON $(\mathrm{P} 4=1)$, upper switch S1 will be OFF $(\mathrm{P} 1=0)$, in the phase "a" leg of inverter, where $\mathrm{h} \boldsymbol{b}$ is the width of the hysteresis band

For Iinv> $\left(\mathrm{I}^{*}\right.$ inv- $\left.\mathrm{h} b\right)$, lower switch S4 will be OFF $(\mathrm{P} 4=0)$, upper switch S1 will be ON $(\mathrm{P} 1=1)$, in the phase "a" leg of inverter. 
The switching pulses for the other remaining three legs can be derived from the same principle.

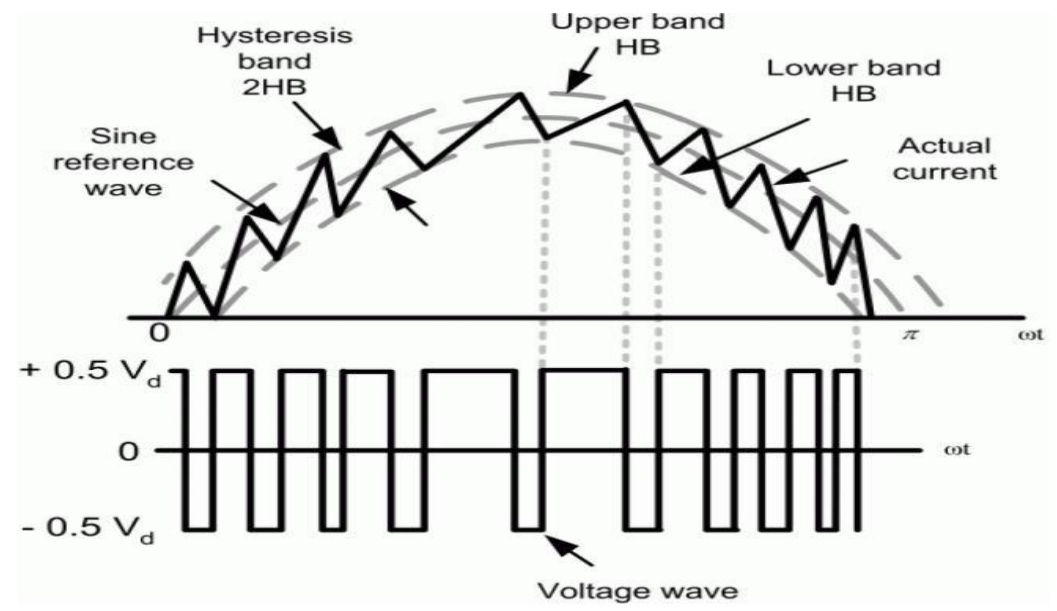

Fig.2. Waveform of hysteresis current control

\section{b. Adaptive hysteresis current control}

In order to get precise and quick response, hysteresis band current control is implemented in the paper to generate the switching pattern. This technique is most suitable for applications of current controlled VSI in active power filters. The Hysteresis band current control is characterized by unconditional stability, very fast response and good accuracy (LIU F et,al,2006) with several limitations such as uneven switching frequency that causes acoustic noise and difficulty in bringing input filters. The conventional hysteresis band current control compose of hysteresis around the reference line current. The reference line current of a active power filter is referred to as $\mathrm{I} c$ and the actual line current of a active power filter is referred to as Ic.

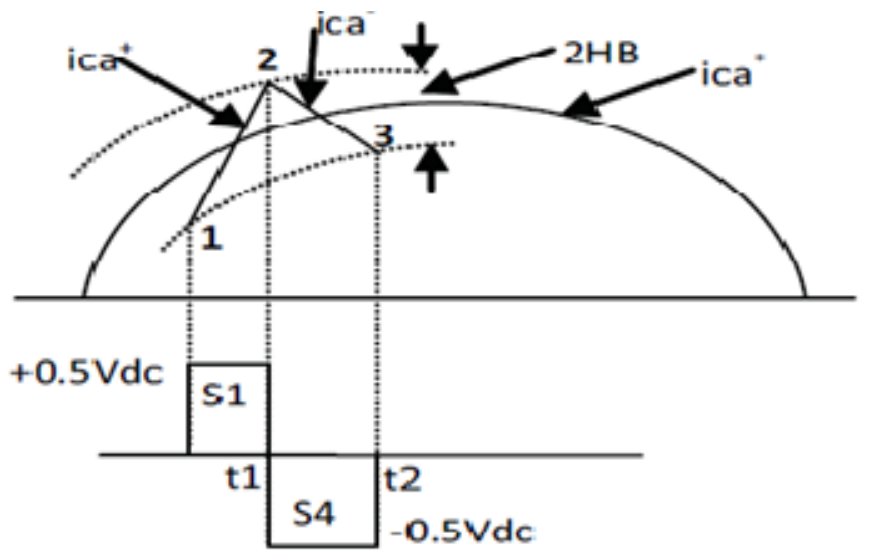

Fig.3. Waveform of Adaptive hysteresis current control

The switching pattern of active power filter is decided by adaptive hysteresis band current controller.

For ica< $\left(\mathrm{ica}^{*}-\mathrm{HB}\right)$, lower switch is $\mathrm{ON}$ and upper switch is OFF for leg "a" of inverter. For ica> (ica $\left.{ }^{*}+\mathrm{HB}\right)$, lower switch is OFF and upper switch is ON for leg "a" of inverter.

The adaptive hysteresis current control bandwidth expression is given as:

$H B=\frac{0.125 V_{D C}}{f_{c L}}\left[1-\frac{4 L^{2}}{V_{D C}^{2}}\left(\frac{v_{a}}{L}+m\right)^{2}\right]$

Where $\overline{f c}=$ modulation frequency,

In order to control the switching pattern of the inverter, Hysteresis band (HB) is modulated at different points of fundamental frequency cycle. For symmetrical operation of all three phases, it is expected that the hysteresis bandwidth (HB) profiles $H B a, H B b$ and $H B c$ will be same, but have phase difference. 


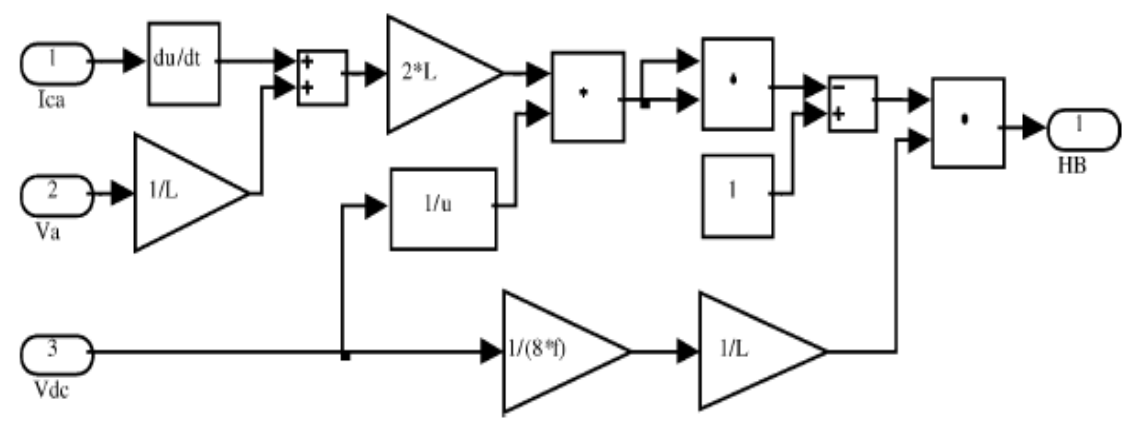

Fig.4. Block diagram of adaptive hysteresis band

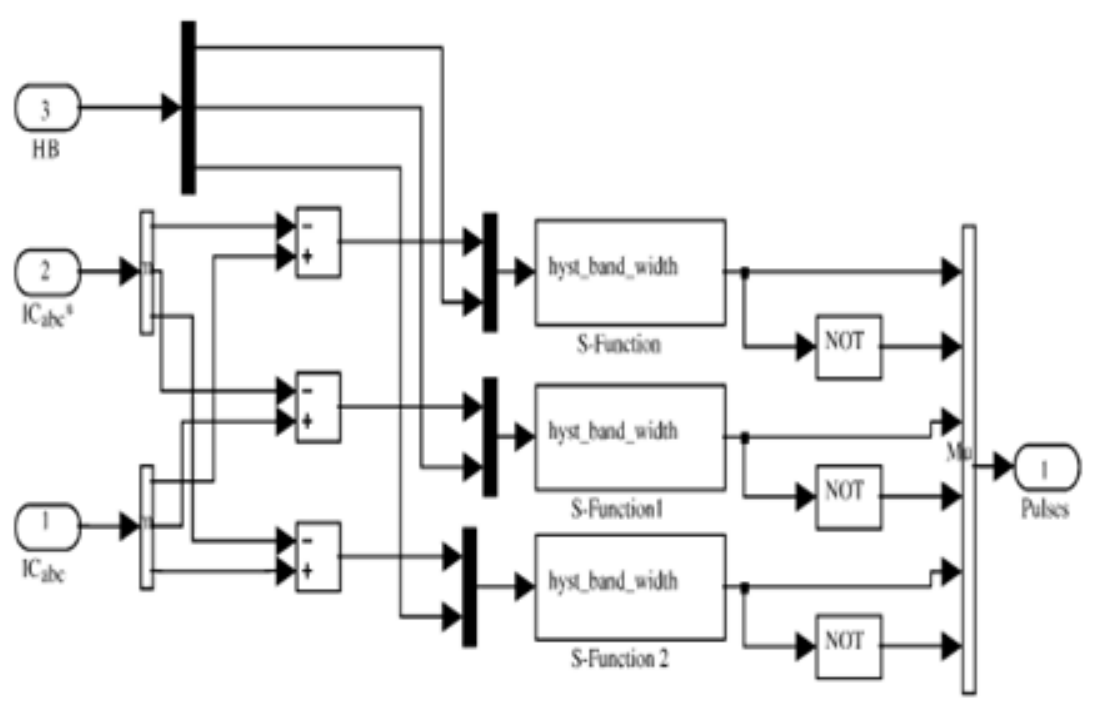

Fig.5. Block diagram of adaptive hysteresis current control

III. SIMULATION RESULTS

The simulation is carried out in MATLAB/SIMULINK Software for the proposed work. The performance comparison has been done between HCC without D-STATCOM and AHCC. The performance comparison is given from Fig.6 to Fig.9.

\section{A. Performance of the system without D-STATCOM}

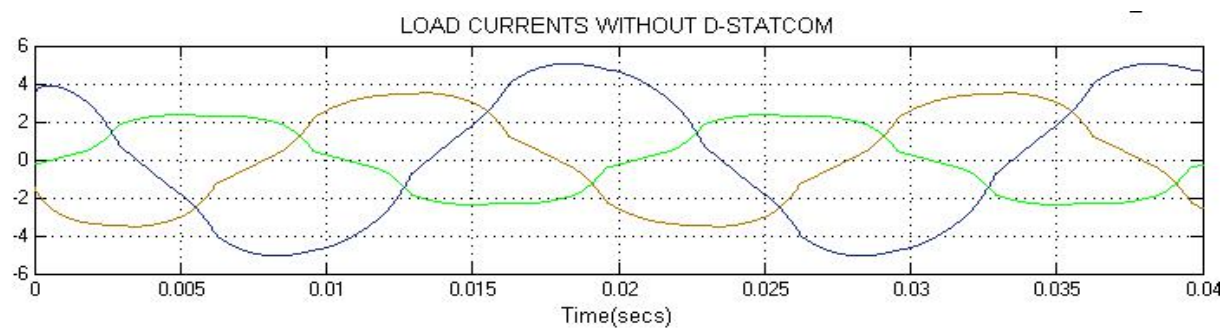

Fig.6 Load currents without D-STATCOM

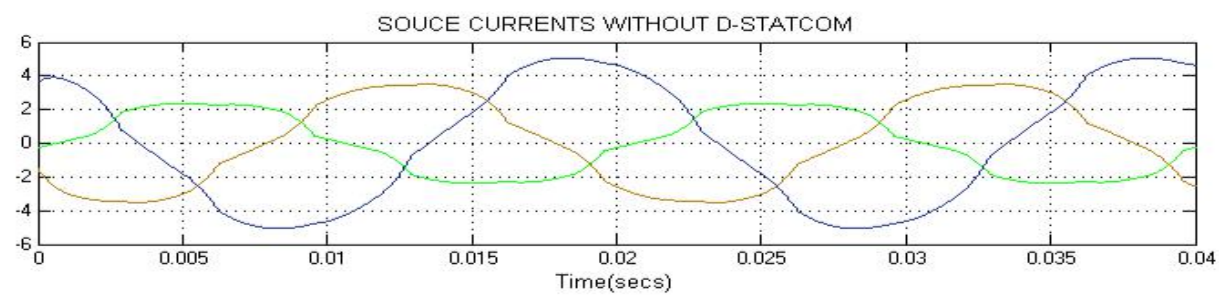

Fig.7 Source currents without D-STATCOM 


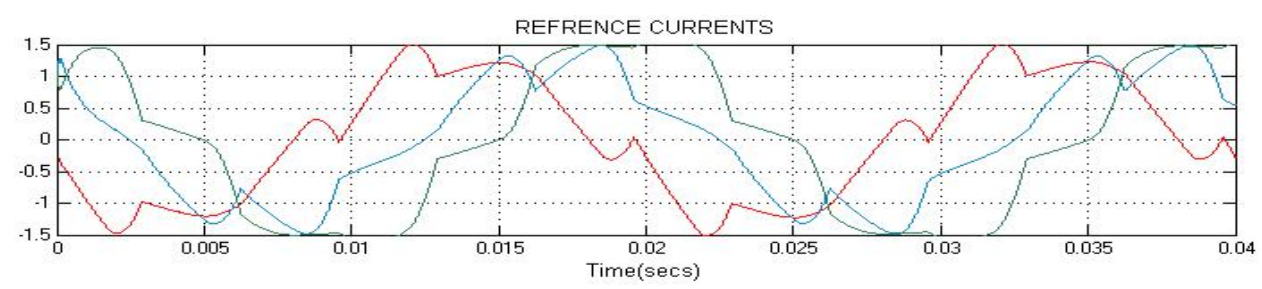

Fig.8.Reference currents

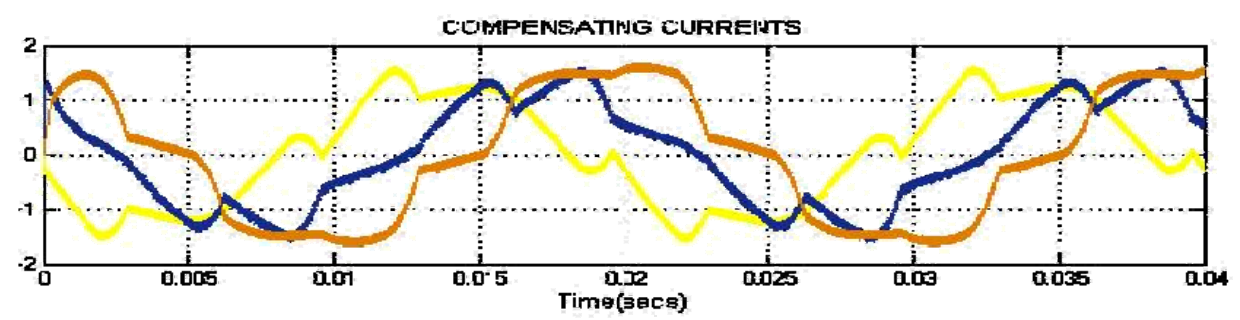

Fig.9.Compensating currents

a. THD Analysis without D-STATCOM

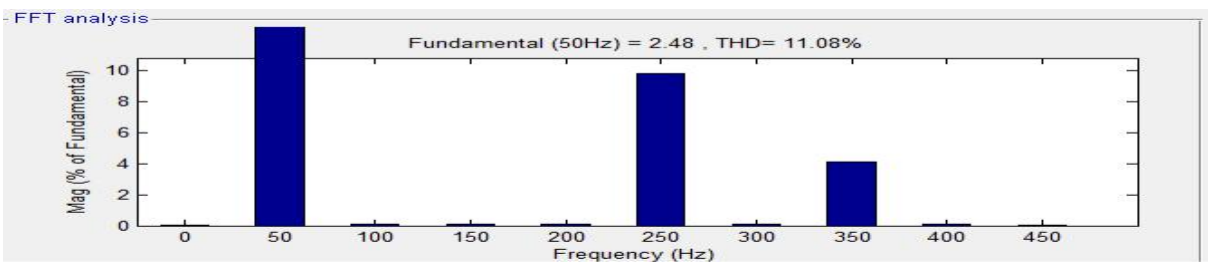

Fig.10. Source current THD without D-STATCOM

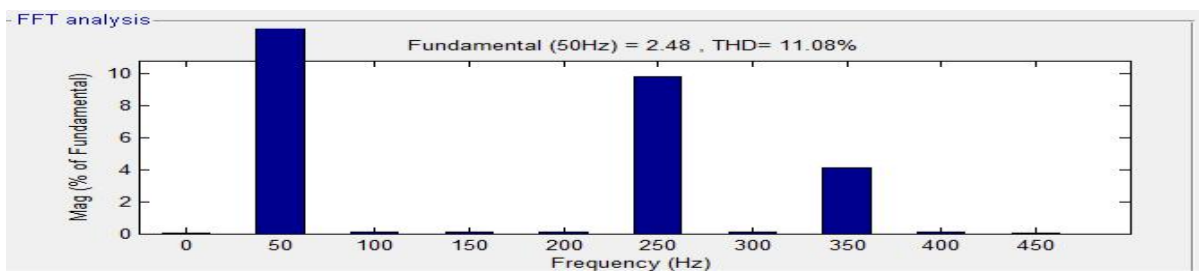

Fig.11. Load current THD without D-STATCOM

The above Fig.10 and Fig.11shows the source current and load current Total harmonic distortion (THD) is $11.08 \%$.

B. Performance of the system with D-STATCOM using HCC

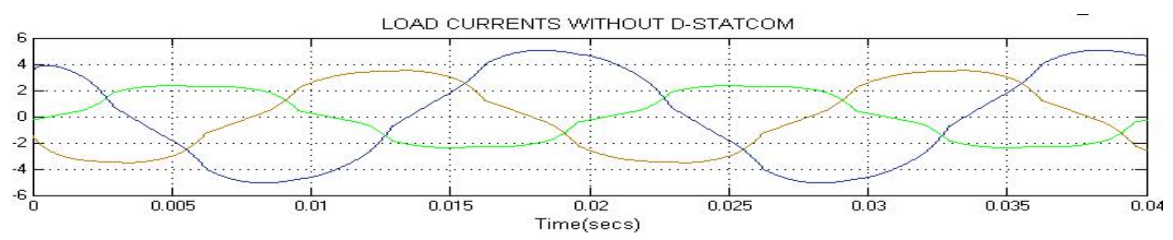

Fig.12. Load currents with D-STATCOM using HCC

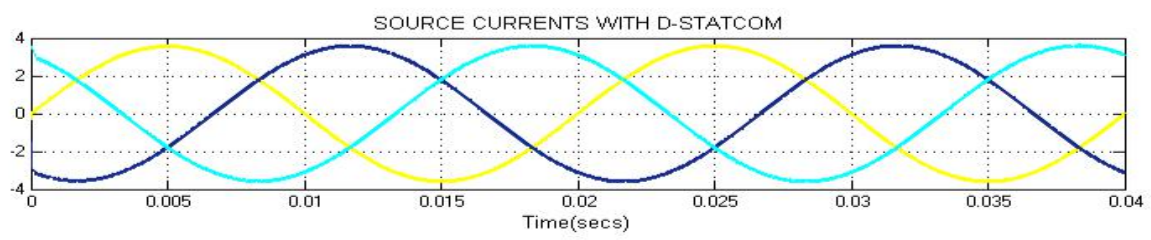

Fig.13. Source currents with D-STATCOM using HCC 
b. THD Analysis with D-STATCOM

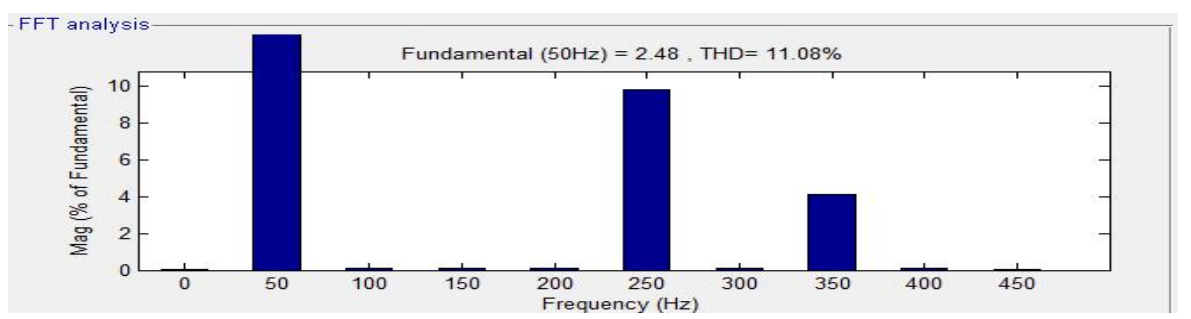

Fig.14. Load current THD with D-STATCOM using HCC

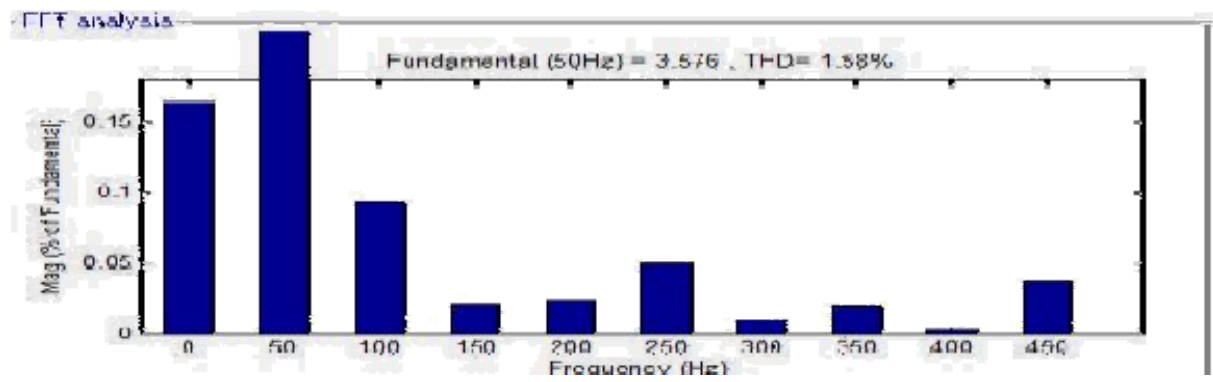

Fig.15. Source current THD with D-STATCOM using HCC

The above Fig.14 and Fig.15. shows the simulation response of load and source current THD. Here we can see that the load current THD is $11.08 \%$ and source current THD is $1.58 \%$. This THD value is less as compared to source current THD without D-STATCOM as shown in fig. 10

\section{Performance of the system with D-STATCOM using AHCC}

The performance of the system with AHCC can be shown from the below results and the THD of the system with AHCC can be obtained from FFT analysis.

LOADCURRENTS WITHOUT D-STATCOM

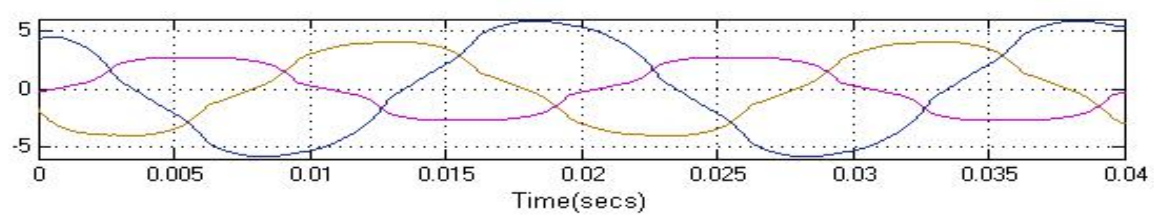

Fig.16. Load current with D-STATCOM using AHCC

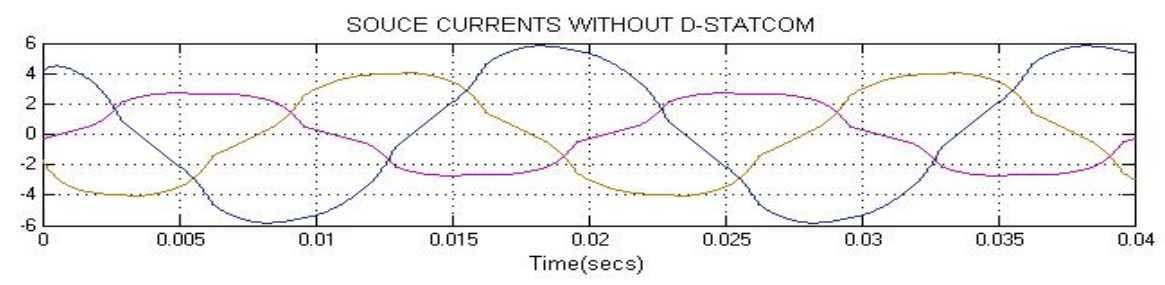

Fig.17. Source current with D-STATCOM using AHCC

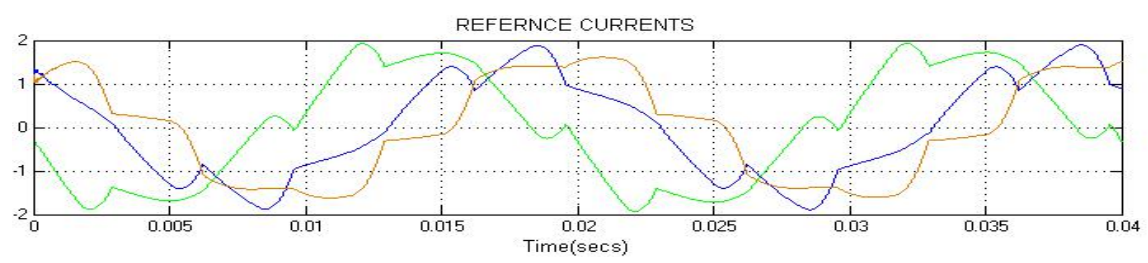

Fig.18.Reference currents 


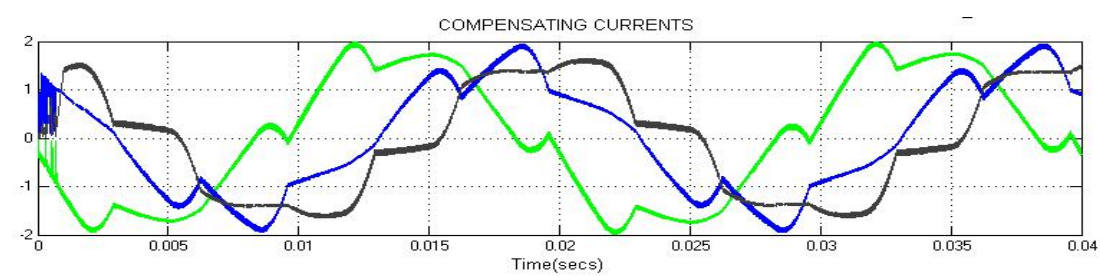

Fig.19.Compensating currents

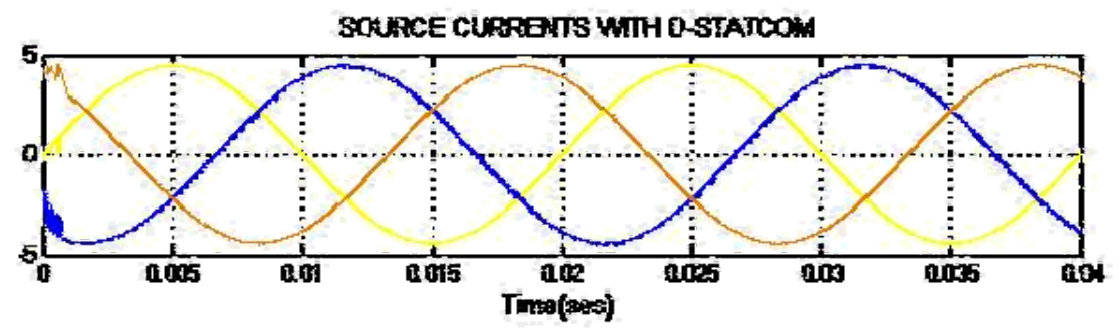

Fig.20.Source current with D-STATCOM using AHCC

c. THD Analysis with D-STATCOM using AHCC

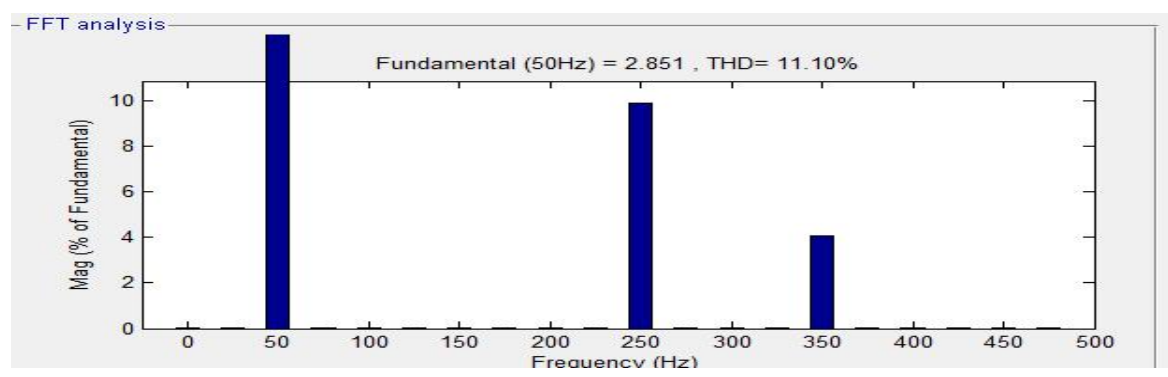

Fig.21. Load current THD with D-STATCOM using AHCC

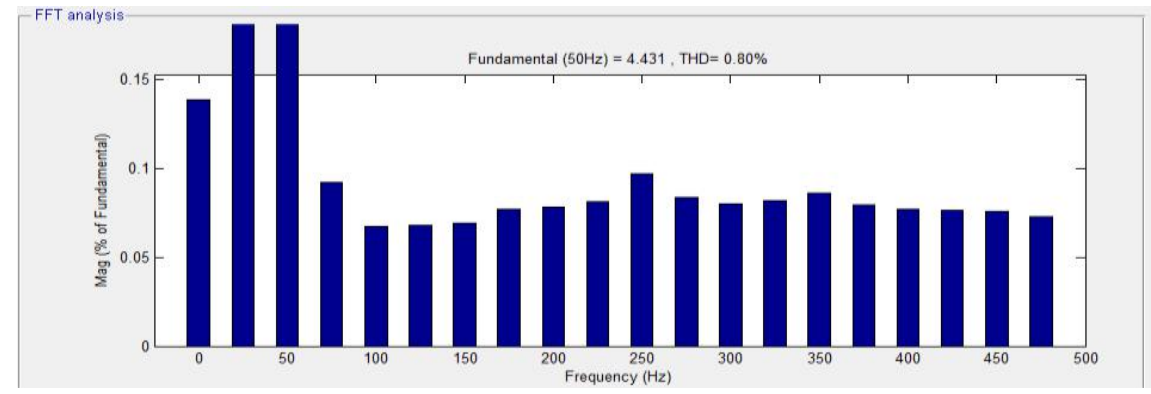

Fig.22.Source current THD with D-STATCOM using AHCC

The above Fig.21 and Fig.22 shows the simulation response of load and source current THD. Here we can see that the load current THD is $11.10 \%$ and source current THD is $0.80 \%$. This THD value is less as compared to source current THD with D-STATCOM using HCC as shown in fig. 15

TABLE I.THD Analysis with D-STATCOM

\begin{tabular}{|c|c|c|}
\hline Type of controller & $\begin{array}{c}\text { Load } \\
\text { current \%THD }\end{array}$ & $\begin{array}{c}\text { Source } \\
\text { current \%THD }\end{array}$ \\
\hline $\begin{array}{c}\text { Hysteresis current } \\
\text { controller }\end{array}$ & 11.08 & 1.58 \\
\hline $\begin{array}{c}\text { Adaptive } \\
\text { Hysteresis current } \\
\text { controller }\end{array}$ & 11.10 & 0.80 \\
\hline
\end{tabular}

Comparison of source current and load current THD by using two different controllers as shown in above table. Here we can see that adaptive Hysteresis controller has less THD as compared to Hysteresis controller. 


\section{IV.CONCLUSION}

Three phase shunt active power filter with AHCC has been implemented in the paper. Reference currents are extracted from the distorted line currents utilizing the instantaneous symmetrical components theory, facilitating improvement of power quality parameters such as reactive power and harmonics due to non-linear load. Results indicate that for various load conditions, easy control of DC- capacitor voltage and the harmonic current can be achieved from the proposed technique. Performance of D-STATCOM with variable hysteresis and the fixed hysteresis switching controllers are verified with simulation results. The THD of the source current after compensation by using HCC and AHCC is $1.58 \%, 0.80 \%$ which is less than $5 \%$, the harmonic limit imposed by the IEEE-519 \& IEC-6000-3 standard.

\section{APPENDIX}

\begin{tabular}{|c|c|}
\hline System parameters: & Ratings \\
\hline Rated source voltage & 200V (peak value) \\
\hline Supply frequency & $50 \mathrm{~Hz}$ \\
\hline Load parameters: & $\mathrm{RL}=300 \Omega$ \\
\hline Non-Linear load & $\mathrm{LL}=0.9864 \mathrm{H}$ \\
\hline Unbalanced load & $26+\mathrm{j} 62.14 \Omega$ \\
& $34+\mathrm{j} 123.27 \Omega$ \\
& $60+\mathrm{j} 187.42 \Omega$ \\
\hline Switching frequency & $8 \mathrm{KHZ}$ \\
\hline DC link capacitor & $2000 \mu \mathrm{F}$ \\
\hline Vdc & $600 \mathrm{~V}$ \\
\hline Fixed hysteresis Band & \pm 0.5 \\
\hline
\end{tabular}

\section{REFERENCES}

[1] B.K. Bose, An adaptive hysteresis band current control technique of a voltage feed PWM inverter for machine drive system, IEEE Trans. Ind. Electron. 37 (5) (1990) 402-406.

[2] LIU F., MASWOOD A.I.: 'A novel variable band hysteresisband current control of three-phase three-level unity PFrectifier with constant switching frequency', IEEE Trans.Power Electron, 2006, 21, (6), pp. 1727-1734.

[3] S. Srikanthan,M.K. Mishra, R.K.V. Rao,Improved hysteresis current control ofthree-level inverter for distribution staticcompensator application,Published in IET Power ElectronicsReceived on 8th May 2008 Revised on 14th November 2008doi: 10.1049/ietpel.2008.0126.

[4] Srinivas BhaskarKaranki, Mahesh K. Mishra,SynchronousReference Frame Based CurrentController with SPWM SwitchingStrategy forD-STATCOM Applications, 2012 IEEE International Conference on Power Electronics, Drives and Energy SystemDecember1619, 2012, Bengaluru, India

[5] P. Salmeron and S. Litran, "Improvement of the electric power qualityusing series active and shunt passive filters," IEEE Transactions onPower Delivery, vol. 25, no. 2, pp. 1058 -1067, April 2010.

[6] S. Iyer, A. Ghosh, and A. Joshi, "Inverter topologies for DSTATCOMapplications-a simulation study," Electric Power Systems Research,vol. 75, no. 2-3, pp. 161-170, 2005.

[7] B. Singh, P. Jayaprakash, and D. Kothari, "A T-connectedtransformerand three-leg VSC based DSTATCOM for power quality

[8] improvement,'IEEE Transactions on Power Electronics, vol. 23, no. 6, pp. 2710 -2718,Nov. 2008.

[9] R. Herrera and P. Salmeron, "Instantaneous reactive power theory: Areference in the nonlinear loads compensation," IEEE Transactions onIndustrial Electronics, vol. 56, no. 6, pp. 2015 -2022, June 2009

[10] Mahesh K Mishra, A. Ghosh, A. Joshi, and H. M. Suryawanshi, "A novel method of load compensation under unbalanced and distorted voltages,'IEEE Transactions on Power Delivery, vol. 22, no. 1, pp. 288 -295, Jan.2007. 